\title{
Use of Rose Bengal, Methylene blue and Curcumin Photosensitizers activated using light emitting diode on post space disinfection bonded to fiber post: An assessment of extrusion bond strength
}

\author{
Fayez Hussain Niazi', Zeeshan Qamar' \\ Mohammed Noushad ${ }^{3}$, Abdullah Khaled Bin Muhareb ${ }^{4}$
}

\begin{abstract}
Objectives: To evaluate the effect of Rose Bengal (RB), methylene blue (MB) and curcumin used as a canal disinfectant on the extrusion bond strength (EBS) of FRCP (fiber reinforced composite resin) with canal dentin.

Methods: The present invitro study was completed in 90 days approved by Riyadh Elm University. Forty premolars were extracted disinfected and decoronated. Mechanochemical preparation was done of canal space using $10 \mathrm{k}$ file widening canals sequentially with a $25 \mathrm{~K}$ file with constant saline irrigation. Canal was dried condensed with gutta percha and sealer. Post space was prepared using peso reamer. Based on canal disinfection samples were divided into four groups. Group-1 MBP+17\%EDTA, Group-2 RBP +17\% EDTA, Group-3 Curcumin+17\% EDTA and Group-4 5.25\% NaOCl +17\% EDTA. Following disinfection, the canal space of all specimens was washed with 17\% EDTA for $120 \mathrm{sec}$. Post was cemented in canal space and cured. Specimens were placed on Universal testing machine (UTM) for EBS. The type of bond failure was evaluated using stereomicroscope. ANOVA and Tukey multiple comparison test was used to compare means.

Results: Cervical third of Group-3 in which samples were disinfected with $\mathrm{CP}+17 \%$ EDTA displayed the maximum EBS $(8.69 \pm 1.32 \mathrm{MPa})$. Whereas, the lowest EBS $(3.30 \pm 0.54 \mathrm{MPa})$ was exhibited by the apical third of Group -4 , where $5.25 \% \mathrm{NaOCl}+17 \%$ EDTA was used as a canal disinfectant. The intragroup comparison demonstrated a declining trend of EBS from cervical to apical third in all investigated groups.

Conclusion: Root canal dentin treated with different PS (MBP, CP, and RBP) demonstrated better EBS than the conventional disinfecting regime $(\mathrm{NaOCl}+17 \%$ EDTA). CP and RBP displayed better EBS than MBP.
\end{abstract}

KEYWORDS: Canal disinfection, Curcumin, Extrusion bond strength, Methylene blue, Rose Bengal.

How to cite this:

doi: https://doi.org/10.12669/pjms.38.1.4780

Niazi FH, Qamar Z, Noushad M, Khaled Bin Muhareb A. Use of Rose Bengal, Methylene blue and Curcumin Photosensitizers activated using light emitting diode on post space disinfection bonded to fiber post: An assessment of extrusion bond strength. Pak J Med Sci. 2022;38(1):34-39. doi: https://doi.org/10.12669/pjms.38.1.4780

This is an Open Access article distributed under the terms of the Creative Commons Attribution License (http://creativecommons.org/licenses/by/3.0), which permits unrestricted use, distribution, and reproduction in any medium, provided the original work is properly cited.

\section{INTRODUCTION}

Correspondence:

Fayez Hussain Niazi

Department of Restorative and Prosthetic Dentistry,

College of Dentistry,

Dar Al Uloom University,

Riyadh, Saudi Arabia.

E-mail: fayezniazi92@gmail.com

* Received for Publication:

* Revision Received:

* Revision Accepted:
May 28, 2021

August 20, 2021

August 30, 2021
The prosthetic or restorative rehabilitation of root-treated teeth usually requires placement of post due to excessive compromise in clinical tooth structure. ${ }^{1}$ Among the different types of posts available, fiber-reinforced composite posts (FRCP) have gained acceptance due to favorable aesthetics, comparable modulus of elasticity to dentin, and acceptable biocompatibility. ${ }^{2}$ Moreover, the adhesive nature of FRCP contributes to the formation of a homogenous monoblock of dentin/ 
post adhesive system which results in long-term clinical success. ${ }^{3}$ Among various factors affecting FRCP in the canal space, the type and concentration of chemical disinfectant largely impact extrusion bond strength (EBS). Chemical disinfection along with mechanical debridement is considered to be a gold standard and widely used method for canal sterilization. ${ }^{3}$

Among the various chemical irrigants used in dentistry, sodium hypochlorite $(\mathrm{NaOCl})$ had gained widespread popularity due to its antimicrobial effectiveness, tissue dissolving properties, and lubrication. ${ }^{4}$ It also possesses low viscosity which allows easy introduction and penetration into the canal space along with adequate shelf life and cost-effectiveness. ${ }^{5}$ However, existing literature advocates that $\mathrm{NaOCl}$ is unable to remove the inorganic component of the smear layer which barricades adhesion of bonded restorations. ${ }^{6}$ Moreover, it displays concentration-dependent cytotoxicity. ${ }^{7}$ Therefore, the use of chelator i.e., ethylenediaminetetraacetic acid (EDTA), and a mixture of doxycycline, acid, and detergent (MTAD) is being recommended as a final canal disinfectant after $\mathrm{NaOCl}$ to achieve complete smear layer removal. However, chemical irrigation contributes to bacterial load reduction yet does not disinfect the canal. ${ }^{7}$

Photodynamic therapy (PDT) has appeared to be a technical innovation that has modernized the concept of canal disinfection. ${ }^{8}$ PDT consist of light of a specific wavelength and photosensitizer (PS) which when absorbs by light generates free radical reactive oxygen species (ROS) ${ }^{8}$ In dentistry, multiple different photosensitizers i.e., methylene blue photosensitizer (MBP), tolonium chloride, photofrin, indocyanine green, and curcumin have been evaluated for their effect on shear bond strength (SBS), EBS, and microleakage. MBP also called methylthioninium chloride, is a cationic phenothiazine derivative. ${ }^{9}$ It becomes activated when irradiated with low-level laser therapy (LLT) with diode lasers at a wavelength of 660 $\mathrm{nm}$. However, the literature showed contradictory outcomes related to its effect on EBS of fiber posts. ${ }^{7-8}$ $\mathrm{CP}$ on the other hand is a relatively new concept for canal disinfection obtained from turmeric powder and achieves antibacterial effectiveness similar to MBP by producing ROS. ${ }^{9}$ However, data related to its effect on PBS of FRCP is scarce. Recently, the role of xanthene-based photosensitizer Rose Bengal (RBP) has been investigated to evaluate its effects as an antimicrobial disinfectant against canal bacteria. ${ }^{10}$ It is an anionic red or rose color dye that belongs to the tetrachloro-tetraiodo derivative of fluorescein. It absorbs light in the wavelength range of visible light $500-800 \mathrm{~nm} .{ }^{11}$ $\mathrm{RB}$ dye is considered an active PS as it generates a significant quantity of singlet oxygen species.

To our knowledge from existing indexed literature, it was found that the effect of $\mathrm{NaOCl}$ on the PBS of FRCP has been studied with conclusive outcomes. However, data related to the role of PDT on EBS of FRCP using different PS (MBP, CP, and RBP) is inconclusive with dubious outcomes. The existing study hypothesizes that PDT using different PS (MBP, CP, and RBP) will display comparable outcomes to PBS of FRCP when canal irrigated with conventional regimes. Therefore, the current in-vitro study aimed to evaluate the effect of different disinfecting regimes on the PBS of FRCP with canal dentin.

\section{METHODS}

A sample of 40 extracted human premolars was collected from clinical settings. The present invitro study was completed in 90 days approved by Riyadh Elm University, FR-335m8. An ultrasonic scaler (Woodpecker U6 Scaler, USA) was used to remove the attached periodontal ligaments, inorganic and organic debris. All samples were stored in $0.4 \%$ thymol solution (Fórmula \& Ação) maintaining the temperature at $4^{\circ} \mathrm{C}$ for 48 hours. Each specimen was de-coronated with a doublefaced diamond disc (KG Sorensen, India) up to cementoenamel junction $\mathrm{CEJ}$ to standardized root length to $15 \mathrm{~mm}$. The present study followed checklist for reporting invitro study CRIS guidelines.

Allthesamplesweresubjected tomechanochemical preparation of root canal by obtaining working length with a $10 \mathrm{~K}$ size hand file (Dentsply; Maillefer Instruments, Ballaigues, Switzerland) keeping $1 \mathrm{~mm}$ above the apical foramen. Canals were then widened by performing sequential filing up to size $25 \mathrm{k}$ file. This was followed by preparing canals with a rotary pro taper system till finishing file F3. During all the mechanical preparation root canals were repetitively irrigated by saline. The canal space of all specimens was dried using paper points (Dentex, Master Endo Dental Absorbent Paper Points) and made ready for obturation with gutta-percha (Radiant Surgident) and AH Plus sealer (Dentsply, Korea).

After root canal completion, peso-reamers (Dentmark, India) were used sequentially (2, 3, 
and 4) to prepare the post space. The gutta-percha was removed up to the length of $10 \mathrm{~mm}$. All the post space were disinfected and were arbitrarily allocated in four different groups based on post space disinfecting agent used $(n=10)$ each group.

Group-I: MBP (Zhejiang Ronsheng Technology Co., Ltd) was used to disinfect the post space in this group. MBP was applied in the canal space for $180 \mathrm{sec}$ before irradiation. MBP was activated using the fiber-optic tip of diode laser (Aarvam Medical Systems, India) at an incidence angle of $90^{\circ}$ with $638 \mathrm{~nm}$ wavelength, $30 \mathrm{~Hz}$ of frequency, and 2 watts of power.

Group-II: In this group samples were disinfected with $25 \mathrm{~mol} / \mathrm{L}$ RB dye which is followed by irradiation with a green laser with peak absorptions at $540 \mathrm{~nm}$. The activation time was of $60 \mathrm{sec}$. The method of activation was using the same fiber optic tip parallel to the long axis of the tooth.

Group-III: CP was placed as a post-space disinfectant in samples of this group. Photoactivation of $\mathrm{CP}$ was done using a light-emitting diode (LED) curing unit (Prototype, Finep/Gnatus LED Edixeon, Edison Opto Corporation, Taiwan) with the radiation intensity of $1200 \mathrm{~mW} / \mathrm{cm} 2$.

Group-IV: In this group, irrigation with 5.25\% $\mathrm{NaOCl}$ (Vardhman Chemi-Sol Industries, India) was performed using a $5 \mathrm{ml} 30$-gauge needle for 60 sec in a to and fro motion.

Following disinfection, the canal space of all specimens was washed with $17 \%$ EDTA for 120 sec. Post Placement: The disinfected post-space of all the specimens were dried with paper points. Within, the canal space glass fiber post (Swastik Dentomed Device, India) was placed after cleaning it with $70 \%$ ethanol. The post space was then air-dried and luted with the fiber post using Panavia F 2.0 (Kuraray Dental, Tokyo, Japan) self-etch dual-cure resin cement. The adhesive cement was cured by using LED (Elipar S10, 3M ESPE, Neuss, Germany). All the samples after cement polymerization were kept and stored for 24 hours in a dark environment maintaining the temperature at $37^{\circ} \mathrm{C}$ and humidity $100 \%$
All the specimen were placed perpendicularly on resin blocks followed by sectioning at coronal, middle, and apical third ( $3 \mathrm{~mm}$ each) using Isomet device (Isomet, Buehler, USA) under constant cooling. The sections were then placed in the universal testing machine (Shimadzu Corporation AutoGraph AGS-X Series, Kyoto-Japan) at $1 \mathrm{~mm} /$ min crosshead speed. The highest force which was applied for extrusion of fiber post segment from the root dentin was measured in Mega Pascal (MPa). Modes of failure were identified with a Stereomicroscope at 40x magnification after EBS.

Statistical Analysis: One-way analysis of variance (ANOVA) assessed the means and standard deviations (SD) of EBS. Tukey multiple comparison tests were used to compare means of EBS $(p=0.05)$.

\section{RESULTS}

Homogeneity of data was assessed using Kolmogorov-Smirnov test. Means and SD values among different experimental groups at the cervical, middle, and apical thirds of the root are displayed in Table-I. From the results, it was observed that the cervical third of Group-3 in which samples were disinfected with $\mathrm{CP}+17 \%$ EDTA displayed the maximum EBS $(8.69 \pm 1.32$ $\mathrm{MPa})$. Whereas, the lowest EBS $(3.30 \pm 0.54 \mathrm{MPa})$ was exhibited by the apical third of Group-4, where $5.25 \% \mathrm{NaOCl}+17 \%$ EDTA was used as a canal disinfectant.

The intragroup comparison demonstrated a declining trend of EBS from cervical to apical third in all investigated groups. The EBS values of the cervical and middle third of all experimental groups were comparable $(p>0.05)$. However, they were statistically different from apical thirds $(p<0.05)$ (Table-I, Fig.1)

The intergroup comparison revealed comparable EBS of Group-2 specimens in which RBP $+17 \%$ EDTA was used as a canal disinfectant at all root levels (apical, middle, and coronal) with

Table-I: Details of photosensitizers used in the present study.

\begin{tabular}{lccc}
\hline Photosensitizer & Charge & Excitation Maximum $(\mathrm{nm})$ & The concentration of PS $\mathrm{mg} / \mathrm{L}$ \\
\hline Rose Bengal Photosensitizer & Anionic & 559 & 100 \\
Curcumin Photosensitizer & Neutral & 547 & 500 \\
Methylene Blue Photosensitizer & Cationic & 632 & 100 \\
\hline
\end{tabular}

Rose Bengal Photosensitizer (RB), Curcumin Photosensitizer (CP), Methylene Blue photosensitizer (MB). 


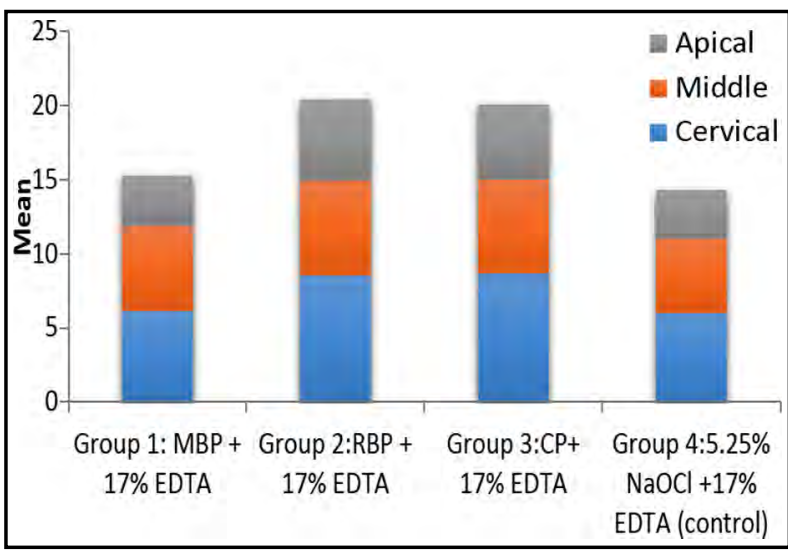

Fig.1: Means of PBS (MPa) values among experimental groups at the cervical, middle, and apical levels of roots. Sodium hypochlorite $(\mathrm{NaOCl})$; Ethylene diamine tetraacetic acid (EDTA). Methylene blue photosensitizer (MBP), Rose Bengal photosensitizer(RBP), Curcumin photosensitizer $(\mathrm{CP})$.

Group-3 ( $\mathrm{p}>0.05)$. Whereas, Group-1 in which post space was irrigated with MBP $+17 \%$ EDTA and Group-4 demonstrated comparable extrusion bond values ( $p>0.05)$.

Failure modes of all experimental groups are presented in Table-II. The majority of the failure mode was adhesive i.e., between cement and dentin. However, the middle third of Group-2 $(\mathrm{RBP}+17 \%$ EDTA $)$ and $3(\mathrm{CP}+17 \%$ EDTA $)$ displayed a cohesive type of failure. (Fig.2)

\section{DISCUSSION}

The present in vitro study was established on the hypothesis that PDT using different PS (MB, $\mathrm{CP}$, and $\mathrm{RB}$ ) will display comparable outcomes of FRCP EBS on radicular dentin irrigated with the conventional regime $\mathrm{NaOCl}+17 \%$ EDTA. To our surprise, the results of the current study revealed that specimens irrigated with PDT displayed better bond integrity of FRCP to root dentinal

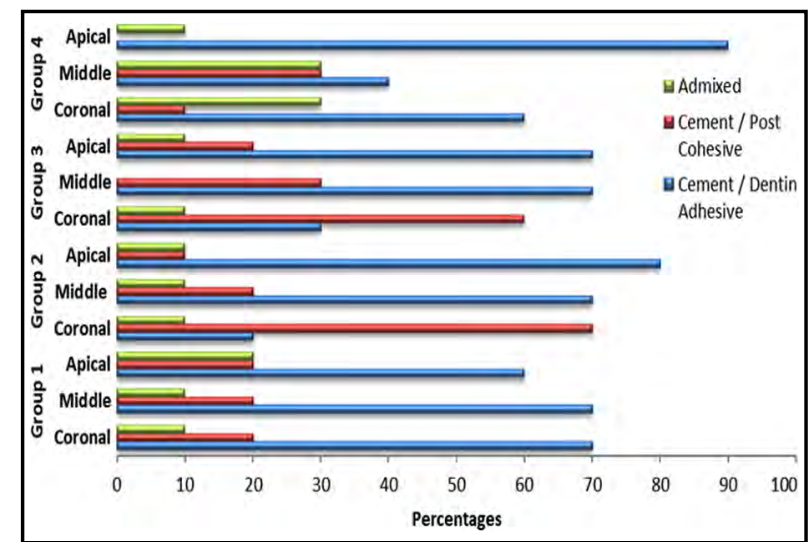

Fig.2: Pattern of fracture according to failure type.

wall at all three levels (coronal, middle apical) than $\mathrm{NaOCl}+17 \%$ EDTA. Hence, the proposed hypothesis was rejected.

Bond integrity between the FRCP and a resin adhesive cement along with bond strength of resin luting agent with the radicular dentin wall is an important factor for clinical longevity and success of root restorative treatment. ${ }^{12-13}$ It was found from the results of the present study that $5.25 \% \mathrm{NaOCl}+17 \%$ EDTA and MBP $+17 \%$ EDTA disinfected specimens showed the lowest and comparable EBS. This reduction in bond scores of self-etching adhesive to post space after irrigation with $\mathrm{NaOCl}+17 \%$ EDTA can be explained by alteration in the redox potential of root dentin due to $\mathrm{NaOCl}$ oxidization and the damage it causes to the organic component of dentin ${ }^{7-14}$ Hence, resin monomer would not be able to penetrate properly into the demineralized dentin which attributes to incomplete polymerization of resin luting cement thus compromising the bond integrity. ${ }^{16,17}$ This can be explained by the concentration of $\mathrm{NaOCl}$ used in the present study. Multiple previous studies have revealed that $5.25 \%$ of $\mathrm{NaOCl}$ decreases bond integrity of resin composite to caries affected

Table-II: Means and Standard deviations (SD) of Push-out bond strength (MPa) values among experimental groups at cervical, middle, and apical levels of root.

\begin{tabular}{lccc}
\hline Groups & Cervical & Middle & Apical \\
\hline Group-1: MBP + 17\% EDTA & $6.13 \pm 0.36^{\mathrm{b}, \mathrm{A}}$ & $5.75 \pm 0.22^{\mathrm{b}, \mathrm{A}}$ & $3.41 \pm 0.18^{\mathrm{b}, \mathrm{B}}$ \\
Group-2: RBP + 17\% EDTA & $8.57 \pm 0.35^{\mathrm{a}, \mathrm{A}}$ & $6.38 \pm 1.11^{\mathrm{a}, \mathrm{A}}$ & $5.46 \pm 0.52^{\mathrm{a}, \mathrm{B}}$ \\
Group-3: CP+ 17\% EDTA & $8.69 \pm 1.32^{\mathrm{a}, \mathrm{A}}$ & $6.30 \pm 0.83^{\mathrm{a}, \mathrm{A}}$ & $5.11 \pm 0.36^{\mathrm{a}, \mathrm{B}}$ \\
Group-4: $5.25 \% \mathrm{NaOCl}+17 \%$ EDTA (control) & $6.01 \pm 1.3^{\mathrm{b}, \mathrm{A}}$ & $5.01 \pm 0.45^{\mathrm{b}, \mathrm{A}}$ & $3.30 \pm 0.54^{\mathrm{b}, \mathrm{B}}$ \\
\hline
\end{tabular}

Sodium hypochlorite (NaOCl); Ethylene diamine tetraacetic acid (EDTA), Different superscript lower-case alphabets denote statistically significant difference within the same column $(p<0.05)$, Data with different upper-case alphabets denotes significant difference within each row. $(\mathrm{p}<0.05)$. 
dentin $^{6,17,18}$, Similarly, a low EBS of MBP treated group can be justified because of the cationic character of the photosensitizer. These cationic molecules bind with anionic phosphate $(\mathrm{P})$ and Calcium $\left(\mathrm{Ca}^{+}\right)$in dentinal structure resulting in modification of $\mathrm{Ca}^{+}$and $\mathrm{P}$ ion ratio. This results in calcio-phosphate precipitation on the surface of canal dentin acting as a physical barrier for resin cement interaction with dentin. ${ }^{13}$ In addition, the hydrophilic nature of MBP also advocated low EBS achieved in the current study.9.1.2.19 Sayhon et al., in a study, explained that that absorbed water by MBP act as a barrier between resin and dentin thus compromising EBS values. ${ }^{20}$ The results of the existing study are following the work by Alonaizan et al. ${ }^{21}$

Furthermore, it was found that specimens, where $\mathrm{CP}$ and RBP were used as post space irrigants, displayed the highest and comparable EBS. A plausible explanation for these results would be the anionic nature of both the PS. However, $\mathrm{CP}$ inherently has neutral properties which upon dissociation forms anions of superoxide and hydrogen peroxide. ${ }^{9,19}$ On the other hand, RBP is anionic by nature. Both the superoxide of Curcumin in dentin structure and RBP are attracted to cationic charged $\mathrm{Ca}^{++}$ions thus causing surface alteration enhancing micromechanical retention of adhesive cement with improved bond integrity. ${ }^{12}$ Moreover, the hydrophobic nature of both $\mathrm{CP}$ and RBP along with hydrophobic cement possibly explains the outcome of better bond strength in these groups. Regarding modes of failure, both the $\mathrm{MBP}$ and $\mathrm{NaOCl}$ conditioned post space exhibited an adhesive type of failure when authenticates the lower bond integrity in these groups. Whereas, coronal sections of both CP and RBP disinfected samples displayed the cohesive failure which further confirms the higher EBS. ${ }^{7,22}$ However, the failure pattern was changed from cohesive to adhesive due to the difference in dentinal tubules from the cervical to the apical section of the root. ${ }^{7}$ The mode of failure observed in investigated groups harmonized with the EBS values. ${ }^{23.24}$

Limitations of the study: The current
study exhibited some inherent methodological limitations. It is speculated that outcomes are influenced by the structural dentin variability at different locations i.e., tubular fluids, odontoblastic process along the root length. The presence of the smear layer, the difference in type and generation of the adhesive system used cannot be overlooked. Moreover, the effect of RBP on shear bond strength (SBS) and EBS either with FRCP with the root dentin or composite restorative material to the cavity dentin needs further investigation. Similarly, scanning electron microscopy (SEM) and Atomic force microscopy (AFM) of radicular dentin after $\mathrm{CP}$ and RBP need proper evaluation. It can also be understood that in vitro study design does not replicate the oral environment thus more in-vivo clinical trials are required to justify the finding of the present study.

\section{CONCLUSION}

Root canal dentin treated with different PS (MBP, CP, and RBP) demonstrated better EBS than the conventional disinfecting regime $(\mathrm{NaOCl}$ $+17 \%$ EDTA). CP and RBP displayed better EBS than MBP. Further, investigation is required in clinical settings to reciprocate the outcomes of the present study.

Acknowledgments: The project was supported and funded by the Deanship of Graduate Studies and Scientific Research at Dar Al Uloom University, Riyadh, KSA.

Conflict of Interest Statement: The authors declare that they have no conflict of interest and all authors have read and approved the final draft.

\section{REFERENCES}

1. Niu D, Xie J, Liu C, Ni S, Liu H. The influence of different treatments on fiber post and root canal to bond strength of fiber post. J Adhes Sci Technol. 2020:928-940. doi: 10.1080/01694243.2020.1829322

2. Z Mohammadi S. Yaripour S. Shalavi F. Palazzi S. Asgary, Root canal irrigants and dentin bonding: An update, Iran Endod J. 12 - Google Search.

3. Alkhudhairy FI, Yaman P, Dennison J, McDonald N, Herrero A, Bin-Shuwaish MS. The effects of different irrigation solutions on the bond strength of cemented fiber posts. Clin Cosmet Investig Dent. 2018;10:221-230. doi: 10.2147/CCIDE.S155688

4. Fundaoglu Kucukekenci F, Kucukekenci AS. Effect of ultrasonic and nd: Yag laser activation on irrigants on the push-out bond strength of fiber post to the root canal. J Appl Oral Sci. 2019;27. doi: 10.1590/1678-77572018-0420

5. Kirmali O, Ustun O, Kapdan A, Kustarc1 A. Evaluation of Various Pretreatments to Fiber Post on the Push-out Bond Strength of Root Canal Dentin. J Endod. 2017;43(7):11801185. doi: 10.1016/j.joen.2017.03.006

6. Alkhudhairy F, Vohra F, Naseem M. Influence of Er,Cr:YSGG Laser Dentin Conditioning on the Bond Strength of Bioactive and Conventional Bulk-Fill Dental Restorative Material. Photobiomodul Photomed Laser Surg. 2020;38(1):30-35. doi: 10.1089/photob.2019.4661 
7. Al Ahdal K, Al Deeb L, Al-Hamdan RS, Bin-Shuwaish MS, Al Deeb M, Maawadh AM et al. Influence of different photosensitizers on push-out bond strength of fiber post to radicular dentin. Photodiagnosis Photodyn Ther. 2020;31:101805. doi: 10.1016/j.pdpdt.2020.101805

8. Alrahlah A, Naseem M, Tanveer SA, Abrar E, Charania A, AlRifaiy MQ et al. Influence of disinfection of caries effected dentin with different concentration of silver diamine fluoride, curcumin and Er, Cr:YSGG on adhesive bond strength to resin composite. Photodiagnosis Photodyn Ther. 2020;32:102065. doi: 10.1016/j.pdpdt.2020.102065

9. Al Deeb L, Bin-Shuwaish MS, Abrar E, Naseem M, Al-Hamdan RS, Maawadh AM, et al. Efficacy of chlorhexidine, Er Cr YSGG laser and photodynamic therapy on the adhesive bond integrity of caries affected dentin. An in-vitro study. Photodiagnosis Photodyn Ther. 2020;31:101875. doi: 10.1016/j.pdpdt.2020.101875

10. Sin JH, Walsh LJ, Figueredo CM, George R. Evaluation of effectiveness of photosensitizers used in laser endodontics disinfection: A systematic review. Transl Biophotonics. 2021;3(1):e202000007. doi: 10.1002/tbio.202000007

11. Li R, Yuan L, Jia W, Qin M, Wang Y. Effects of Rose Bengal- and Methylene Blue-Mediated Potassium IodidePotentiated Photodynamic Therapy on Enterococcus faecalis: A Comparative Study. Lasers Surg Med. 2021;53(3):400-410. doi: 10.1002/lsm.23299

12. Vohra F, Bukhari IA, Sheikh SA, Naseem M, Hussain M. Photodynamic activation of irrigation (using different laser prototypes) on push out bond strength of fiber posts. Photodiagnosis Photodyn Ther. 2020;30:101716. doi: 10.1016/j.pdpdt.2020.101716

13. Al Jeaidi ZA. Influence of resin cements and root canal disinfection techniques on the adhesive bond strength of fibre reinforced composite post to radicular dentin. Photodiagnosis Photodyn Ther. 2021;33. doi: 10.1016/j. pdpdt.2020.102108

14. Al-Madi EM, Al-Jamie MA, Al-Owaid NM, Almohaimede AA, Al-Owid AM. Antibacterial efficacy of silver diamine fluoride as a root canal irrigant. Clin Exp Dent Res. 2019;5(5):551-556. doi: 10.1002/cre2.222

15. S Vaziri, A Kangarlou, R Shahbazi, A Nazari Nasab, $\mathrm{M}$ Naseri. Comparison of the bactericidal efficacy of photodynamic therapy, $2.5 \%$ sodium hypochlorite, and $2 \%$ chlorhexidine against Enterococcous faecalis in root canals; - Google Search.

16. Aljamhan AS, Alrefeai MH, Alhabdan A, Alkhudhairy F, Abrar E, Alhusseini SA. Push out bond strength of glass fiber post to radicular dentin irrigated with Nisin and MTAD compared to methylene blue photodynamic therapy. Photodiagnosis Photodyn Ther. 2021;34:102304. doi: 10.1016/j.pdpdt.2021.102304

17. Chaharom MEE, Kahnamoii MA, Kimyai S, Moghaddam MH. Effect of sodium hypochlorite on the shear bond strength of fifth- and seventh-generation adhesives to coronal dentin. African J Biotechnol. 2011;10(59):1269712701. doi: $10.5897 /$ ajb11.164

18. Vohra F, Labban N, Al-Hussaini A, Al-Jarboua M, Zawawi $\mathrm{R}$, Alrahlah A, et al. Influence of Er;Cr:YSGG Laser on Shear Bond Strength and Color Stability of Lithium Disilicate Ceramics: An in Vitro Study. Photobiomodulation, Photomedicine, Laser Surg. 2019;37(8):483-488. doi: 10.1089 / photob.2018.4582
19. Alshahrani A, Abrar E, Maawadh AM, Al-Hamdan RS, Almohareb T, AlFawaz Y, et al. Management of caries affected dentin (CAD) with resin modified glass ionomer cement (RMGIC) in the presence of different caries disinfectants and photosensitizers. Photodiagnosis Photodyn Ther. 2020;32:101978. doi: 10.1016/j. pdpdt.2020.101978

20. Strazzi Sahyon HB, Silva PP da, Oliveira MS de, Cintra LT, Dezan-Júnior E, Gomes-Filho JE et al. Influence of curcumin photosensitizer in photodynamic therapy on the mechanical properties and push-out bond strength of glass-fiber posts to intraradicular dentin. Photodiagnosis Photodyn Ther. 2019;25:376-381. doi: 10.1016/j. pdpdt.2019.01.025

21. Alonaizan FA, Alofi RS, Alfawaz YF, Alsahhaf A, AlAali KA, Vohra F, et al. Effect of Photodynamic Therapy, Er,Cr:YSGG, and Nd:YAG Laser on the Push-Out Bond Strength of Fiber Post to Root Dentin. Photobiomodulation, Photomedicine, Laser Surg. 2020;38(1):24-29. doi: 10.1089/ photob.2019.4687

22. Alkhudhairy F, Naseem M, Ahmad ZH, Alnooh AN, Vohra F. Efficacy of phototherapy with different conventional surface treatments on adhesive quality of lithium disilicate ceramics. 2019;25:292-295. doi: 10.1016/j.pdpdt.2019.01.015

23. Hashem M, El-Hejazi AA, Niaz MO, Alsadon O, Alolayani BM, Fouad $\mathrm{H}$. Bond strength of root canal filling with radicular dentin previously treated with either photobiomodulation or photodynamic therapy: Effect of disinfection protocols. Photodiagnosis Photodyn Ther. 2020;30:101733. doi: 10.1016/j.pdpdt.2020.101733

24. Maroulakos G, He J, Nagy WW. The Post-endodontic Adhesive Interface: Theoretical Perspectives and Potential Flaws. J Endod. 2018;44(3):363-371. doi: 10.1016/j. joen.2017.11.007

\section{Authors Contribution:}

FHA, ZQ: Data collection, study design, manuscript writing, final manuscript approval.

MN, ZQ: Data collection, study design, manuscript drafting, data analysis, manuscript approval.

FHA, MN: Data collection, manuscript approval, and data interpretation.

AKBM: Data collection, writing, revise, editing, and final manuscript approval.

All authors are responsible and accountable for the accuracy and integrity of the work.

\section{Authors:}

1. Fayez Hussain Niazi,

2. Zeeshan Qamar,

Department of OMFS and Diagnostic Sciences,

Riyadh Elm University,

Riyadh, Saudi Arabia.

Department of Oral Biology,

Liaquat College of Medicine Dentistry,

Karachi. Pakistan.

3. Mohammed Noushad

Universiti Sains Malaysia, Kubang Kerian, Kelantan, Malaysia.

4. Abdullah Khaled Bin Muhareb,

Ministry of Health, Kingdom of Saudi Arabia.

1,3: Department of Restorative and Prosthetic Dentistry, College of Dentistry, Dar Al Uloom University,

Riyadh, Saudi Arabia. 